OPEN ACCESS

Edited by:

Heiko Mühl,

Goethe University Frankfurt, Germany

Reviewed by:

Antonio Recchiuti,

University of Studies G. d'Annunzio

Chieti and Pescara, Italy

Alpdogan Kantarci,

The Forsyth Institute, United States

${ }^{*}$ Correspondence:

Sylvaine You

sylvaine.you@inserm.fr

${ }^{\dagger}$ These authors have contributed equally to this work

Specialty section: This article was submitted to Inflammation,

a section of the journal

Frontiers in Immunology

Received: 31 August 2021 Accepted: 26 October 2021 Published: 16 November 2021

Citation:

Perez-Hernandez J, Chiurchiù V, Perruche $S$ and You $S$ (2021) Regulation of T-Cell Immune Responses by Pro-

Resolving Lipid Mediators.

Front. Immunol. 12:768133. doi: 10.3389/fimmu.2021.768133

\section{Regulation of T-Cell Immune Responses by Pro-Resolving Lipid Mediators}

\author{
Javier Perez-Hernandez ${ }^{1,2 \dagger}$, Valerio Chiurchiù ${ }^{3,4 \dagger}$, Sylvain Perruche ${ }^{5,6}$ and Sylvaine You $^{1 *}$ \\ 1 Université de Paris, Institut Cochin, CNRS, Institut National de la Santé et de le Recherche Médicale (INSERM), Paris, \\ France, ${ }^{2}$ Departament of Nutrition and Health, Valencian International University (VIU), Valencia, Spain, ${ }^{3}$ Institute of \\ Translational Pharmacology, National Research Council, Rome, Italy, ${ }^{4}$ Laboratory of Resolution of Neuroinflammation, \\ European Center for Brain Research, Istituto di Ricovero e Cura a Carattere Scientifico (IRCCS) Santa Lucia Foundation, \\ Rome, Italy, ${ }^{5}$ Université de Bourgogne Franche-Comté, INSERM, Etablissement Français du Sang (EFS) Bourgogne-Franche \\ Comté (BFC), Unité Mixte de Recherche (UMR)1098 Research on Interaction between Graft, Host and Tumor (RIGHT), \\ Interactions Hôte Greffon-Tumeur/Ingénierie Cellulaire et Génique, Fédération Hospitalo-Universitaire Integrated Center for \\ REsearch in inflammatory diseASes (InCREASe), Besançon, France, 6 MED'INN'Pharma, Besançon, France
}

Both the initiation and the resolution of inflammatory responses are governed by the sequential activation, migration, and control/suppression of immune cells at the site of injury. Bioactive lipids play a major role in the fine-tuning of this dynamic process in a timely manner. During inflammation and its resolution, polymorphonuclear cells (PMNs) and macrophages switch from producing pro-inflammatory prostaglandins and leukotrienes to specialized pro-resolving lipid mediators (SPMs), namely, lipoxins, resolvins, protectins, and maresins, which are operative at the local level to limit further inflammation and tissue injury and restore homeostasis. Accumulating evidences expand now the role and actions of these lipid mediators from innate to adaptive immunity. In particular, SPMs have been shown to contribute to the control of chronic inflammation, and alterations in their production and/or function have been associated with the persistence of several pathological conditions, including autoimmunity, in human and experimental models. In this review, we focus on the impact of pro-resolving lipids on T cells through their ability to modulate T-cell responses. In particular, the effects of the different families of SPMs to restrain effector T-cell functions while promoting regulatory $T$ cells will be reviewed, along with the underlying mechanisms. Furthermore, the emerging concept of SPMs as new biological markers for disease diagnostic and progression and as putative therapeutic tools to regulate the development and magnitude of inflammatory and autoimmune diseases is discussed.

Keywords: resolution, adaptive immunity, autoimmunity, $\mathrm{T}$ cell, therapy, specialized pro-resolving lipid mediators (SPMs), chronic inflammation

\section{INTRODUCTION}

The natural resolution of inflammation is a tightly controlled dynamic process that engages several molecular and cellular mediators to prevent excessive and/or chronic immune responses and tissue damage that may compromise organ function. Indeed, a dysregulation of this process has been incriminated in many inflammatory disorders (1-5). While the mechanisms regulating the onset of 
inflammation have been well characterized for almost a century and are mainly carried out by innate immune cells, which release pro-inflammatory lipids (i.e., eicosanoids: prostaglandins, leukotrienes, and thromboxanes) and cytokines/chemokines, the first endogenous mechanisms that terminate the inflammatory response have been identified exactly 20 years ago and now comprise over 25 lipid mediators derived from polyunsaturated fatty acids (PUFAs) and collectively termed specialized pro-resolving mediators (SPMs). The biosynthesis of all SPMs identified to date is initiated by the enzymatic addition of oxygen to four dietary PUFAs, namely, $\omega-6$ arachidonic acid (AA), $\omega-3$ eicosapentaenoic acid (EPA), $\omega-3$ docosahexaenoic acid (DHA), and $\omega-3$ docosapentaenoic acid (DPA), by means of the stereoselective and concerted action of the very same enzymes used for eicosanoid production, namely, the lipoxygenase (LOX) isozymes, the cyclooxygenase-2 (COX2 ), and, to a minor extent, the cytochrome P450 (6).

SPMs include distinct families of bioactive lipids: AA-derived lipoxins $\left(\mathrm{LXA}_{4}\right.$ and $\left.\mathrm{LXB}_{4}\right)$, EPA-derived E-series resolvins (RvE1-RvE4), DHA-derived D-series resolvins (RvD1-RvD6), protectins (PD1 and PDX), and maresins (MaR1-MaR2), together with their respective sulfide-conjugates in tissue regeneration (RCTR1-3, PCTR1-3, and MCTR1-3), DPA-derived 13-series resolvins (RvT1-RvT4), and $\mathrm{RvD}_{\mathrm{n}-3 \mathrm{DPA}}$ (Figure 1). These lipid mediators, identified between 2001 and 2021 in the laboratory of Prof. Serhan in many tissues during acute inflammation (inflammatory exudates, plasma, brain, lymph nodes, etc.), are mostly produced locally by professional phagocytes [tissueresident macrophages, recruited monocytes, immature dendritic cells (DCs)] and also by vascular endothelial cells and fibroblasts, to some extent. They act as "immunoresolvents," i.e., immune-pharmacological agents of resolution (distinct from immunosuppressive agents), and induce (i) cessation of leukocyte infiltration and stimulation of nonphlogistic recruitment of mononuclear cells, (ii) macrophage-mediated phagocytosis of apoptotic polymorphonuclear cells (efferocytosis) and cellular debris, (iii) killing and clearance of pathogens, (iv) production of anti-inflammatory mediators while inhibiting secretion of proinflammatory cytokines and reactive oxygen species, (v) shortening time of resolution and activation of endogenous resolution programs, and (vi) promotion of tissue regeneration and healing (5-7).

SPMs trigger their pro-resolving signals via specific transmembrane $G$ protein-coupled receptors (GPCRs) that display a variable level of redundancy and include FPR2 (or ALX), GPR32 (or DRV1), GPR18 (or DRV2), ChemR23 (or ERV), BLT1 (or LTB4R/GPR16), LGR6, GPR37, ROR $\alpha$, and GPR101 $(8,9)$. Of note, each SPM can act by activating different receptors, and each receptor is often engaged by several SPMs, which can also compete with pro-inflammatory lipids for binding. For instance, leukotriene B4 (LTB4) and RvE1/E2 are both ligands for BLT1 but exert opposite effects by respectively acting as an agonist (i.e., favoring neutrophil survival) or an antagonist (promoting neutrophils apoptosis) $(10,11)$.

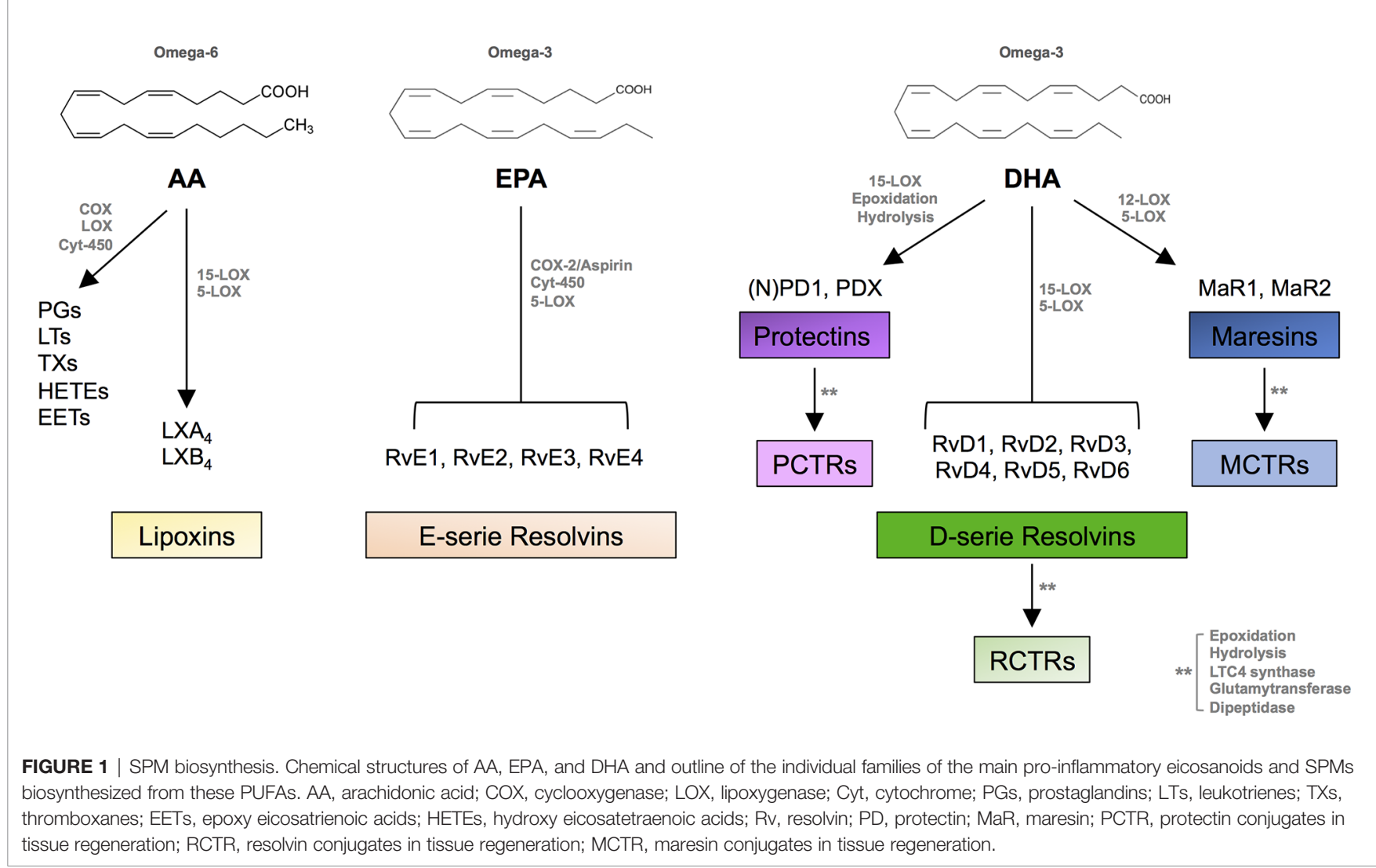


The role of SPMs has been extensively explored in the context of inflammation-resolution operated by innate immune cells (mainly neutrophils and monocytes/macrophages) to resolve acute inflammatory diseases and infections $(12,13)$. However, accumulating evidence now pleads for an additional direct action of SPMs on the adaptive immune system and highlights their capacity to prevent the transition into chronic inflammation (5, $14,15)$. Indeed, $\mathrm{T}$ lymphocytes express SPM receptors and are sensitive to omega-3- and omega-6-derived bioactive lipids, which, in the local microenvironment, can exert pro- or antiinflammatory actions and thus influence $\mathrm{T}$-cell fate and functions. More generally, it becomes increasingly clear that the mechanisms controlling $\mathrm{T}$-cell responses and resolution of inflammation are tightly linked.

In this review, we will present in both human and mouse the evidence highlighting the role of SPMs, in comparison to their pro-inflammatory lipid counterparts, in the regulation of T-cell responses and T-cell-mediated immunity and autoimmunity. We will also discuss their putative usage as biomarkers of disease development or progression as well as therapeutic agents to restore tissue and immune homeostasis through their direct and/or indirect targeting of T cells.

\section{PRO-INFLAMMATORY LIPID MEDIATORS AND T CELLS}

The first evidence for a role and action of bioactive lipids on $\mathrm{T}$ cells has been documented in the early 2000s by studies uncovering the capacity of pro-inflammatory leukotrienes (LTs), especially of LTB4, to mediate effector T-cell (Teff) recruitment to inflammatory sites. Indeed, activated $\mathrm{CD} 4^{+}$and $\mathrm{CD}^{+}$Teff express the LTB4 high affinity receptor BLT1 but not naïve $\mathrm{T}$ cells $(16,17)$. LTB4 chemoattractant property was demonstrated in experimental models of peritonitis (16), asthma (18), transplantation (19), airway hyperresponsiveness $(20,21)$, and oxazolone (OXA)-induced contact dermatitis (22). T-cell trafficking into peripheral tissues was impaired in BTL1deficient mice or in mice treated with a BLT1 antagonist, leading to the reduction of inflammation, graft rejection (19), and airway responsiveness (21). Adoptive transfer models using $\mathrm{BLT}^{+/+}$ versus $\mathrm{BLT}^{-/-} \mathrm{CD}^{+} \mathrm{T}$ cells further strengthened the key role of the LTB4-BLT1 pathway in the migration of Teff to inflamed tissues or tumoral niches and the development of immune responses $(16,20,21,23)$. In vitro studies on mouse and human $\mathrm{T}$ cells confirmed the capacity of LTB4 to promote effector function by increasing Th1 (IFN- $\gamma$ ), Th2 (IL-4), and Th17 (IL-17) cell migration and responses while decreasing Foxp $3^{+}$regulatory T cells (Tregs) in polarization assays $(17,24$, 25). LTB4 was also shown to induce the differentiation of $\mathrm{T}$ follicular helper ( $\mathrm{Tfh}$ ) cells from naïve $\mathrm{T}$ cells, which activate naïve B cells to form germinal centers (26).

Prostaglandins (PGs) also affect T-cell responses through binding to the E-prostanoid receptors (EP)1-4 (27). Notably, PGE2 boosts and expands Th1 and Th17 cells, which express EP2 and EP4, while inhibiting Th2 cells (28). T cells deficient for
EP4 are insensitive to PGE2 and downregulate IL-12 and IFN- $\gamma$ receptor expression, reducing their in vivo pathogenicity (28). Similarly, administration of EP antagonists impaired the development of experimental arthritis, psoriasis, and multiple sclerosis through the inhibition of Th1 and Th17 responses (2931). These pro-inflammatory effects are in line with the capacity of PGE2 to dampen the differentiation of type 1 regulatory T cells (Tr1) (32) and Foxp3 $3^{+}$Tregs (33), although some contradictory results were reported (34). Overall, both LTs and PGs, being central in the perpetuation of inflammatory signals that are at the basis of the transition from acute to chronic inflammation, act as "cytokine amplifiers" by stimulating almost all Teff subsets (Figure 2).

\section{IMMUNOMODULATORY ROLE OF SPMS ON PATHOGENIC T CELLS}

T-cell activation and differentiation into T helper (i.e., Th1, Th2, Th17, Th22 cells) or cytotoxic subsets is instrumental to fight pathogens. They must, however, be controlled and limited in space and time to avoid T-cell hyperactivation, a hallmark of chronic inflammation and autoimmunity. Accordingly, an increasing number of recent studies in mice and humans now document the capacity of several families of SPMs to inhibit pathogenic T cells (Figure 2), thereby contributing to the resolution of inflammation.

Initial studies on the effect of SPMs on T cells came from lipoxins, whereby LXA4 and LXB4 inhibited ERK-dependent TNF- $\alpha$ secretion from peripheral $T$ cells stimulated with antiCD3 antibody (35). These effects were mediated by the LXA4 receptor FPR2/ALX, expressed at a higher level on activated $\mathrm{CD} 25^{+}$and memory $\mathrm{CD} 45 \mathrm{RO}^{+} \mathrm{CD} 4^{+} \mathrm{T}$ cells, with respect to their $\mathrm{CD}^{-} 5^{-}$and naïve $\mathrm{CD} 45 \mathrm{RA}^{+} \mathrm{CD} 4^{+}$counterparts $(35,36)$. Accordingly, treatment with LXA4 inhibited Th1 and Th17 activation, as observed in vivo in the cervical draining lymph nodes of mice with dry eye disease (37), and in vitro using peripheral blood from healthy donors (38). LXA4 was also reported to differentiate naïve $\mathrm{CD}^{+} \mathrm{T}$ cells from tonsils and peripheral blood into Tfh cells in an FPR2-dependent manner (26).

The evidence that the other SPM families were capable of modulating $\mathrm{T}$-cell responses was first unveiled through indirect studies showing reduced T-cell migration into target organs and decreased production of inflammatory cytokines after SPM in vivo administration in various experimental models of inflammation (detailed in the last section and Table 1). The capacity of SPMs to directly impact T-cell response was demonstrated by Chiurchiù and colleagues, who extended these observations to RvD1, RvD2, MaR1, and aspirin-triggered RvD3. Indeed, these SPMs were able to reduce the pro-inflammatory activity of both human $\mathrm{CD} 4^{+}$and $\mathrm{CD} 8^{+} \mathrm{T}$ cells upon stimulation of their $\mathrm{T}$-cell receptor, to inhibit cytokine production by circulating Th1 and Th17 cells, and to prevent Th1 and Th17 commitment of naïve $\mathrm{CD}^{+}{ }^{+} \mathrm{T}$ cells, without, however, impacting $\mathrm{T}$-cell viability and proliferative capacity (52). These findings 

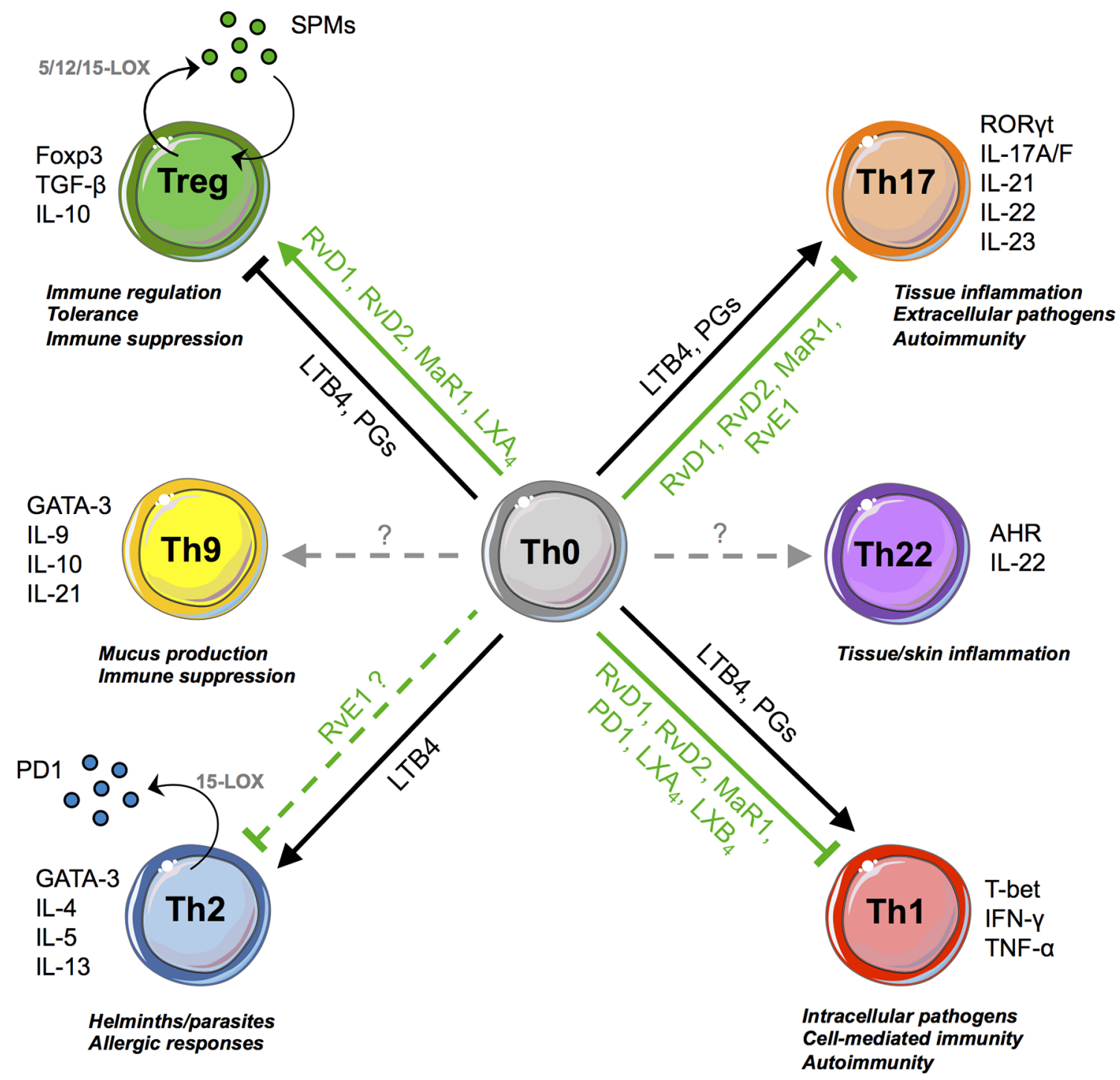

FIGURE 2 | SPMs and T-cell responses. SPMs and pro-inflammatory lipids promote or inhibit, in opposite ways, T-cell differentiation (from Th0 precursors to Tregs, Th1, Th2, Th17). Th2 and Treg cells are also able to biosynthesize few SPMs, such as 17R-RvD3, RvD4, MaRn-3DPA, and PD1, respectively.

were also supported by the in vivo evidence that mice deficient for elongase 2, the key enzyme involved in the biosynthesis of DHA, the precursor of D-resolvins, protectins, and maresins, showed increased percentages of Th1 and Th17 cells, which were reduced upon dietary supplementation with DHA or in vivo treatment with RvD1 (52). Of note, the capacity of SPMs to prevent Th17 polarization was also observed in patients with inflammatory diseases such as rheumatoid arthritis or systemic lupus erythematosus $(59,63)$. Interestingly, RvD1, RvD2, and MaR1 were not capable to modulate IL-4 production and Th2-cell development in vitro (which may, however, not reflect in vivo processes) (52). These results are in line with studies reporting that, in Th2-driven pathologies and mouse models, DHA-derived SPMs like RvD1 and PD1 do not affect IL-4 release and might ameliorate clinical outcome by acting on different cellular targets $(64,65)$.

In contrast, RvE1, which is derived from EPA, was reported to promote resolution of asthmatic airway inflammation and atopic dermatitis by reducing Th2 cytokines; however, evidence of a direct T-cell targeting is missing (66-68). Although data supporting the suppressive effect of RvE1 on Th1, Th2, and Th17 cells are mostly indirect, obtained either upon in vivo administration or in vitro stimulation of dendritic cells $(39,40$, $42,66-71)$, a very recent study showed that this bioactive lipid can directly impact Th17 development by inhibiting their IL-6 and TGF- $\beta$-induced polarization (72). The effect of SPMs on other T helper subsets like Th22 and Th9, either direct or indirect, is still unknown. 
TABLE 1 | In vivo treatment with SPMs and impact on T-cell subsets and functions.

\section{HSV-induced stromal keratitis (SK)/mouse}

Imiquimod (IMQ) challenge-induced psoriasis/mouse Corneal allograft/mouse

Ligature-induced periodontitis/mouse

Hypersensitivity skin model/mouse

Femoral artery wire injury/mouse

Endotoxin-induced uveitis/rat

Experimental autoimmune encephalomyelitis/mouse

OVA-induced allergic eye disease (AED)/mouse

Experimental autoimmune neuritis (EAN)/rat

60,000 ng/kg/day for 8 days(topical, eye)

$8,000 \mathrm{ng} / \mathrm{kg} /$ day (iv)

$50,000 \mathrm{ng} / \mathrm{kg}$ at day 0 and 7 (subconjunctival)

$140 \mathrm{ng} / \mathrm{kg} /$ day for 10 days (topical)

$10,000 \mathrm{ng} / \mathrm{kg} /$ day at day $-1,0$, and 5 (iv)

$8,000 \mathrm{ng} / \mathrm{kg} /$ day (ip) (2 days before surgery)

10 to $1,000 \mathrm{ng} / \mathrm{kg}$ (iv/intravitreal)

$5,000 \mathrm{ng} / \mathrm{kg} /$ day for 40 days (oral)or during 15 days starting at day 7 (ip)

$1,000 \mathrm{ng} / \mathrm{kg} /$ day for 7 days (topical)

$5,000 \mathrm{ng} / \mathrm{kg} /$ day for 12 days (ip)

Ischemia/reperfusion-induced acute kidney injury/mouse $\quad 5,000 \mathrm{ng} / \mathrm{kg} /$ day for 3 days (iv)

DHA deficiency $\left(E l o v 12^{-/}\right) /$mouse

RvD1/ Concanavalin A-induced hepatitis/mouse

RvE1

RvD2 Porphyromonas gingivalis-induced experimental periodontitis/mouse

PD1 Zymosan A-induced peritonitis/mouse IMQ-induced psoriasis/mouse

HSV-induced stromal keratitis (SK)/mouse

MaR1 OVA-induced allergic inflammation/mouse

Collagen-induced arthritis/mouse

IMQ-induced psoriasis/mouse
$5,000 \mathrm{ng} / \mathrm{kg} / \mathrm{day}$ with $50 \mu \mathrm{g}$ of anti-CD3 (ip) $10,000 \mathrm{ng} / \mathrm{kg} /$ day (iv)

$25,000 \mathrm{ng}$ for 3 days plus $5,000 \mathrm{ng}$ for 6 days (over 2 weeks) (ip)

$5,000 \mathrm{ng} / \mathrm{kg}, 2 \mathrm{~h}$ prior to challenge (iv)

$10-1,000 \mathrm{ng} / \mathrm{kg} /$ day for 7 days (sc)

$15,000 \mathrm{ng} / \mathrm{kg}$ twice/day for 10 days(topical, eye)

$50 \mathrm{ng} / \mathrm{kg} /$ day for 4 days (iv)

$5,000 \mathrm{ng} / \mathrm{kg} /$ day for 16 days (iv)

$8,000 \mathrm{ng} / \mathrm{kg} /$ day for 5 days (topical) $\downarrow \|-23$ and $\|-6$ and cell infiltrate within the bronchoalveolar lavage fluid.

$\uparrow$ Th1/Th17 ratio.

$\downarrow$ SK severity

$\downarrow$ cornea influx of neutrophils, Th1 and Th17 cells, IFN- $\gamma$, and IL-6.

$\downarrow$ psoriasis severitySuppression of IL-23-producing DCs and $\gamma \delta$ T cells,

$\uparrow$ graft survival

$\downarrow$ Th1 and Th17 infiltration and edema into the graft and draining lymph

nodes

$\downarrow$ bone loss

$\downarrow$ T-cell infiltrate and preservation of Tregs.

$\downarrow$ ear swelling

$\downarrow$ IFN- $\gamma$-producing $C D 8^{+} T$ cells in the skin

$\downarrow T$-cell recruitment to perivascular areas.

$\downarrow$ IFN- $\gamma$ and IL-2 mRNA levels in injured arteries.

$\downarrow$ uveitis.

neutrophils, T and B cells, M1 macrophages infiltration

$\downarrow$ TNF- $\alpha$, CXCL8, and RANTES in the eye.

$\downarrow$ disease severity

$\downarrow$ autoreactive $T$ cell infiltration

$\downarrow$ AED score

$\downarrow$ conjunctival immune cells (except macrophages).

Enhanced EAN recovery

$\downarrow$ effector $T$ cells.

$\uparrow$ Tregs and IL-10, TGF- $\beta$.

$\uparrow$ Tregs and alleviated renal tubular injury.

$\downarrow$ serum levels of IFN- $\gamma$, TNF- $\alpha$, and IL-6 in a ALX/FPR2-dependent

pathway.

$\downarrow$ IFN- $\gamma$ and IL-17 by peripheral blood CD4 $4^{+} T$ cells

$\downarrow$ liver injury

$\downarrow \mathrm{CD}^{+}$and $C D 8^{+}$T-cell liver infiltration, inflammatory cytokines, and NF-

$\kappa \mathrm{B} / \mathrm{AP}-1$ activity.

Prevent alveolar bone loss

$\downarrow$ Th1 priming and chronic IFN- $\gamma$ secretion.

$\uparrow$ pro-resolving macrophages in the gingiva.

$\downarrow$ Tregs.

$\downarrow$ T-cell infiltration in the peritoneum

$\downarrow$ psoriasis severity $\downarrow$ inflammatory cytokines in lesion and serum

$\downarrow$ Th1/Th17 cells in spleen

$\downarrow$ SK severity

$\downarrow$ infiltration of neutrophils and pathogenic $\mathrm{CD} 4^{+} \mathrm{T}$ cells

$\downarrow$ inflammatory cytokines, chemokines, and angiogenic factors in the

cornea

$\uparrow$ Tregs

$\downarrow$ IL-13 secretion by ILC2 in the bronchoalveolar lavage fluid

$\downarrow$ arthritis severity $\uparrow$ Treg/Th17 ratio (draining lymph node)

$\downarrow$ skin inflammation

$\downarrow \mathrm{IL}$-17-producing CD4 ${ }^{+}$and $\gamma \delta \mathrm{T}$ cells in the skin 


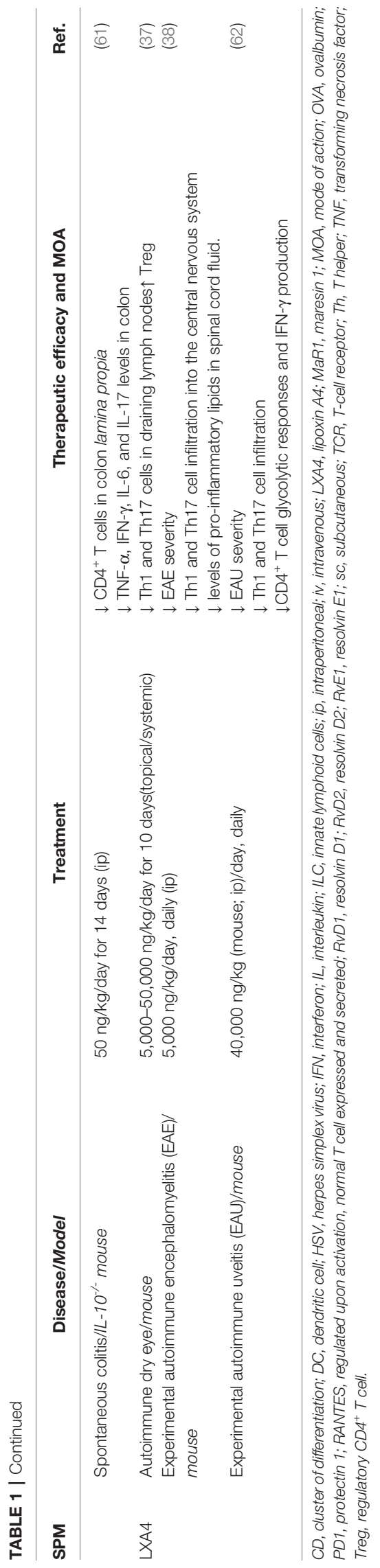

SPM-mediated modulation of T-cell fate and function is associated with the expression of several SPM receptors, including ALX/FPR2, GPR32, GPR18, BLT1, and ChemR23, with higher levels reported on activated and effector cells (albeit at significantly lower levels compared to innate immune cells), indicating that activated $\mathrm{T}$ cells are more responsive to SPMs in general $(35,36,52)$. However, clear data on their expression and signaling pathway in the different T-cell subsets remain currently very limited and deserve further investigations. Accordingly, human Th1 express higher mRNA levels of ALX/FPR2 and also higher protein levels of GPR32 compared to Th0 (52), while Th17 express higher protein levels of both GPR32 and ChemR23 $(52,72)$. These receptors account for the reported effects of RvD1 and RvE1 in reducing Th1 and Th17 responses. The role of the other SPM-binding receptors in mediating the effects of RvD2, PD1, and MaR1 remains to be explored. This may be related to their more recent discovery, such as GPR37 that was identified as the PD1 receptor in 2018 and investigated only in macrophages (73) or LGR6, the surface receptor for MaR1, identified in 2019 and mainly expressed in neutrophils and macrophages, with little expression on total $\mathrm{CD}^{+} \mathrm{T}$ cells (74). Thus, additional thorough studies are necessary at the systemic and tissue levels to better decipher the expression profile and activity of SPM receptors on T cells, which may account for their activation, migration, and control.

Lastly, while it is now well documented that $\mathrm{T}$ cells can respond to several SPMs, little information is known about their capacity to produce pro-resolving lipids. As yet, only one study reported that human Th2-polarized peripheral blood mononuclear cells (PBMCs) with IL-4, but not IL-12/IFN $\gamma$ polarized Th1 cells, produced PD1 in a 15-LOX-dependent manner (55). However, due to likely cellular contaminants in the experimental setting using total PBMC and not highly purified naïve $\mathrm{CD} 4 \mathrm{~T}$ cells, the possibility that other IL-4responding cell types (i.e., monocytes and dendritic cells) were the source of PD1 cannot be ruled out.

\section{IMPACT OF SPMS ON REGULATORY T CELLS}

Among all T-cell subsets, Tregs are arguably the one that fits the most with the concept of resolution of inflammation due to their crucial role in maintaining immune equilibrium and homeostasis (75). They not only play a vital role in the prevention of autoimmunity and the maintenance of self-tolerance but have also been shown to promote macrophage pro-resolving functions, i.e., efferocytosis through an IL-13/IL-10/Vav1 pathway, expression of SPM receptors, and SPM production in target tissues $(76,77)$. Of note, recent studies suggest that the abundance and function of Tregs change during inflammation and that the pool of peripheral Tregs is diverse and can derive from other pathogenic T helper cells; for instance, Th17 can transdifferentiate into Tregs during the resolution of inflammation (78). 
Despite the key role of Tregs in regulating immune and tissue homeostasis, the experimental evidence reporting the impact of SPMs on these tolerogenic T cells dates back only to 2015, first with the in vitro demonstration of the direct effect of MaR1 in amplifying the TGF- $\beta$-induced de novo generation of Foxp $3^{+}$ Tregs (iTregs) (58), and second with the in vivo observation of an increased frequency of Foxp3-expressing $\mathrm{T}$ cells after $\mathrm{LXA}_{4}$ treatment (37). These findings were extended to RvD1, RvD2, and MaR1 in the human setting, with iTregs showing increased CTLA-4 expression, IL-10 release, and suppressive capacity (52). However, although mice genetically unable to produce SPMs (Elovl $2^{-1-}$ mice) displayed decreased proportion of Foxp $3^{+}$Tregs, none of the tested SPMs was capable, per se, to induce Foxp3 expression and convert naïve $\mathrm{CD} 4^{+} \mathrm{T}$ cells into Tregs without the required TGF- $\beta$-enriched polarizing milieu (52).

The positive impact of SPMs on Foxp $3^{+}$Tregs was further corroborated in vivo upon administration of SPMs (mainly RvD1, LXA4, and MaR1) in several experimental models of chronic inflammatory or neurodegenerative diseases, although the enhanced Treg proportion observed in these contexts may be due to both direct and indirect effect on T cells $(50,51,59,63,79)$ (Table 1). Of note, a majority of these studies also reported an improved Treg/Th17-Th1 balance in the target tissue or draining lymph nodes, associated with SPM therapeutic efficacy. Concerning PD1, its in vivo administration has recently been associated with increased frequency of IL-10-producing $\mathrm{CD} 4^{+} \mathrm{T}$ cells in the colon, suggesting an impact on $\operatorname{Tr} 1$ cells (80). Yet, no evidence has been reported for a role of this DHA-derived SPM on Foxp $3^{+}$Tregs.

Only two studies have examined which receptor might be involved in mediating the SPM-induced Treg generation. Both studies focused on RvD1 and, by using neutralizing antibodies, they demonstrated that GPR32 was responsible for the Foxp $3^{+}$ Treg differentiation in humans (52), while ALX/FPR2 was at play in mice (51).

Interestingly, a recent work reported that human and mouse Foxp $3^{+}$Tregs express the 5/12/15-lipoxygenases and are able to biosynthetize several SPMs from all four major bioactive metabolomes, but only 17R-RvD3, RvD4, and MaRn-3DPA were significantly produced at a higher amount compared to naïve CD ${ }^{+} \mathrm{T}$ cells (81). Genetic ablation of ALOX15 in Tregs decreased Foxp3 expression and altered their transcriptional and metabolic programs, resulting in impaired suppressive function and increased effector pathways. Also, Foxp3 binding elements were identified in the ALOX15 promoter region, allowing a direct positive regulation of ALOX15 expression by Foxp3 (81).

Collectively, these findings demonstrate that SPMs can target different T-cell subsets to modulate their development and functions, and emphasize the pro-resolving and homeostatic actions of SPMs (Figure 2). They also pinpoint that mechanisms driving immune regulation and resolution of inflammation are complementary and interconnected, which supports the potential of new therapeutic opportunities. Additionally, SPMs may be produced not only by innate immune cells but also by $\mathrm{T}$ cells, possibly exerting autocrine and paracrine anti-inflammatory actions, ultimately contributing to immune regulation.

\section{DEFECTIVE PRO-RESOLVING PATHWAYS ASSOCIATED WITH PATHOGENIC T-CELL RESPONSES}

Chronic diseases are characterized by excessive inflammation and impairment of natural resolution mechanisms. Bioactive lipids are implicated in the pathologic processes, with an unbalanced production of inflammatory over pro-resolving lipids, driving the aberrant recruitment and activation of immune cells, including effector $\mathrm{T}$ lymphocytes, leading to tissue damage and ultimately disease symptoms (5). Pathogenic $\mathrm{T}$-cell responses have been associated with defective resolution pathways and disease progression. However, so far, few studies have investigated and demonstrated a direct link between a deficient SPM pathway and exacerbated T-cell reactivity.

In experimental models of autoimmune dry eye disease or autoimmune neuritis (mimicking human inflammatory demyelinating polyradiculoneuropathy), reduced $\mathrm{RvD1}$ or LXA4 amounts correlated with decreased proportion of Foxp3 ${ }^{+}$ Tregs in the inflamed tissues, respectively $(37,50)$. In humans, the BLT1 receptor was found upregulated on T cells isolated from the airways of patients presenting obliterative bronchiolitis after lung transplantation (19), or from the blood of asthmatic patients (82). These data suggest an increased T-cell sensitivity to pro-inflammatory LTB4 and a critical role of BLT1 in T-cell recruitment into target organs as evidenced in animal models. Conversely, $\mathrm{T}$ cells from patients with chronic heart failure expressed reduced levels of GPR32 as compared to healthy subjects, correlating with an impaired responsiveness of $\mathrm{CD} 4^{+}$ and $\mathrm{CD}^{+} \mathrm{T}$ cells to RvD1 and RvD2 (assessed by the inhibition of inflammatory cytokine production) (83). In the context of multiple sclerosis (MS), ALX/FPR2, GPR32, GPR18, and ChemR23 were differentially expressed on PBMCs according to disease activity, with decreased mRNA levels in patients with progressive MS as compared to patients presenting relapsing or remitting MS (84). Of note, while BLT1 showed similar expression in all donor groups, these SPM receptors were globally upregulated in relapsing or remitting MS compared to healthy donors, which may reflect the engagement of resolution mechanisms in immune cells, including $\mathrm{T}$ cells, in response to inflammation and autoimmunity. Lastly, a recent study showed that LXA4 modulated in vitro activation, TNF- $\alpha$, IFN- $\gamma$, IL-17 production, and transendothelial migration capacity of $\mathrm{CD} 4^{+}$ and $\mathrm{CD} 8^{+} \mathrm{T}$ cells from both healthy donors and patients with relapsing-remitting MS (38). However, we have to keep in mind that these analyses were performed on circulating $\mathrm{T}$ cells, not on tissue-infiltrating $\mathrm{T}$ cells, which may exhibit distinct functional characteristics and behavior influenced by the local inflammatory/resolving lipid balance.

Of interest, in the last years, lipidomic analysis of plasma or serum recovered from patients with chronic inflammatory disorders implicating pathogenic T-cell responses constantly showed decreased SPM concentrations at the time of active disease, compared with healthy and/or inactive disease status. This was reported for MaR1 and PD1 in rheumatoid arthritis (RA) $(59,85)$ and for RvD1 in SLE, MS, and chronic heart failure 
$(63,83,84)$. Lower levels of RvD3, RvD4, and RvE3 were also observed in a small cohort of stage III RA patients, with concomitant increase in inflammatory TBX2 (86). In some instances, SPM abundance negatively correlated with disease severity $(63,84,85)$. Similarly, patients with leprosy and acute Th1-mediated inflammatory episodes showed reduced plasma levels of RvD1 as compared to patients without Th1 hyperreactivity (87). In most cases, opposite patterns were observed for arachidonic acid-derived inflammatory lipids (LTB4, PGs), which were found in higher abundance at the time of progressive disease.

However, available information is overall limited, and caution should be brought on the interpretation of these results. Indeed, depending on the clinical context, higher levels of plasmatic SPMs can be detected in patients presenting inactive/controlled inflammatory and autoimmune pathologies as compared to healthy individuals, which may reflect perturbed resolution processes related to an attempt to counteract inflammation. In addition, systemic levels of bioactive lipids may not coincide with tissue abundance, and a decrease in the SPM level could result from higher consumption, reduced production, or both conditions. Lastly, expression of SPM receptors on T cells and their responsiveness to SPMs have so far been explored in few pathological contexts. These investigations need to be extended to additional immune disorders to better understand the impact of resolutive pathways on effector and regulatory $\mathrm{T}$-cell subsets and to identify putative failures at the systemic and tissue levels, which may contribute to the defective immune regulation leading to disease progression.

Thus, these findings call for further deciphering, in mice and humans, the impact of resolution mechanisms and the SPM pathway on adaptive immunity, in particular their role in the dysregulated effector/regulatory $\mathrm{T}$-cell responses responsible for the progression and chronicity of immune and autoimmune diseases.

\section{IN VIVO THERAPEUTIC EFFICACY OF SPMS THROUGH T-CELL REPROGRAMMING}

The potent pro-resolving properties of SPMs have encouraged their therapeutic application in various experimental models of inflammation (Table $\mathbf{1}$ and Figure 3). Particularly, RvD1 and RvE1, but also RvD2, MaR1, PDX, and LAX4, have been tested in a number of pathological contexts presenting resolution defects accentuated by effector T-cell infiltration and activity in target organs.
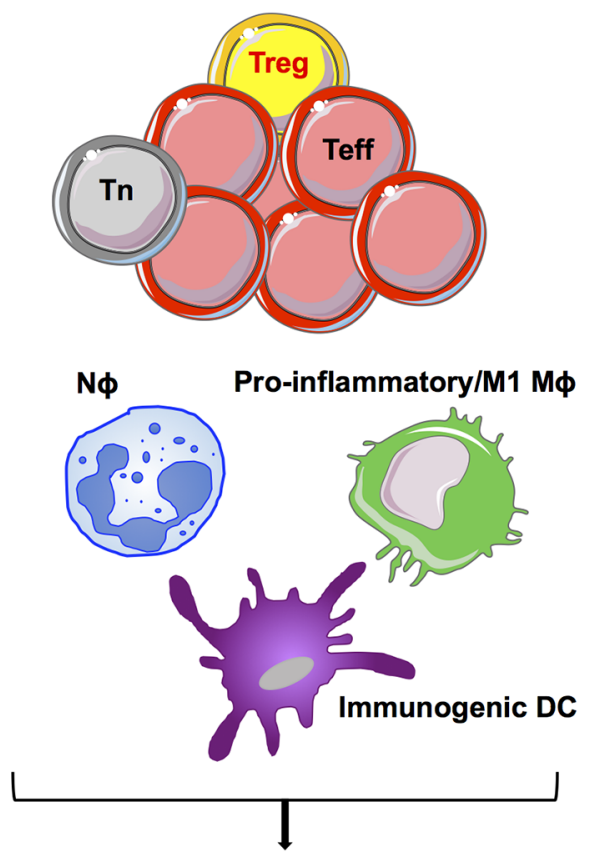

\section{Excessive/chronic inflammation Autoimmunity and tissue damage}
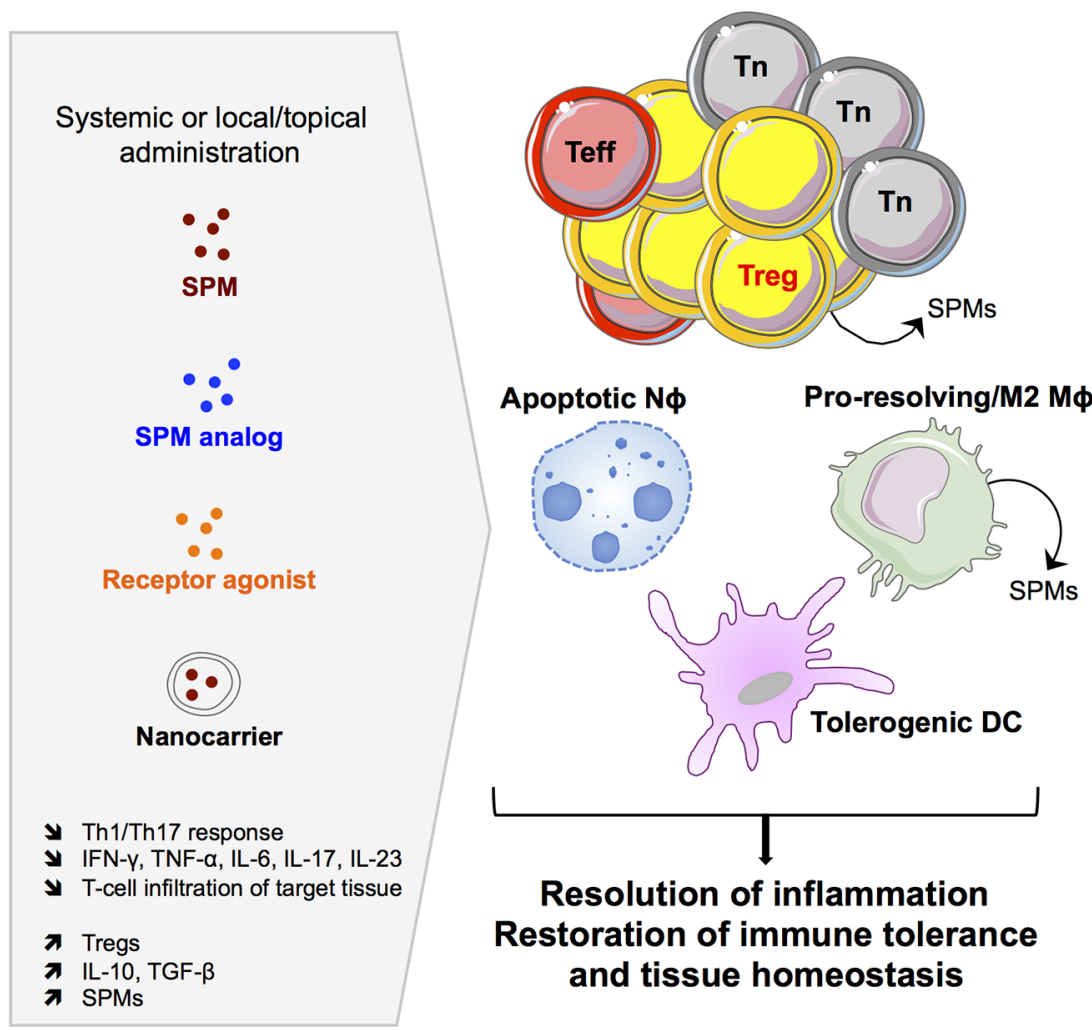

Resolution of inflammation Restoration of immune tolerance and tissue homeostasis

FIGURE 3 | SPM-based therapeutic opportunities. Targeting the SPM pathway can impact innate and adaptive immune cells to induce efficient resolution of excessive inflammatory responses and to restore immune tolerance and tissue homeostasis. N $\phi$, neutrophil; M $\phi$, macrophage; DC, dendritic cell; Teff, effector T cell; Tn, naïve T cell; Treg, regulatory $\mathrm{T}$ cell. 
The protocols used were very variable depending on the model: SPMs were administered through systemic (intravenous, intraperitoneal) or local (topical application on the eye, intravitreal, subconjunctival) routes, at an average dose of $5 \mu \mathrm{g} / \mathrm{kg}$, i.e., approximately $100 \mathrm{ng} /$ mouse (ranging from 20 to $500 \mathrm{ng}$ /injection), with single or repeated injections over several weeks.

Overall, SPM treatment reduced the severity of inflammatory diseases (in most cases experimentally induced in animal models), marked by decreased tissue damage, immune cell infiltration, and inflammatory cytokines. Indeed, Th1 and Th17 cells were repeatedly found in lower numbers in target organs and draining lymph nodes, together with less in situ expression (mRNA and/or protein) of IFN- $\gamma$, TNF- $\alpha$, IL-17, IL6 , and IL-1 $\beta$ in the context of endotoxic uveitis $(46,47)$, concanavalin-A-induced hepatitis (53), sepsis-induced lung injury (88), stromal keratitis (herpes simplex virus-induced ocular inflammatory lesions) $(40,57,89)$, periodontitis (43, 54), and rheumatoid arthritis (59, 85). Similar positive outcomes were observed in allergic manifestations such as chronic allergic eye disease (49), allergic airway inflammation (39), and psoriatic dermatitis (41). SPM therapy has been explored in few autoimmune diseases, i.e., RvD1 in Sjögren's syndrome (90) and SLE (63), and LXA4 in experimental autoimmune uveitis (EAU) (62) and encephalomyelitis (EAE) (38), with here again the amelioration of symptoms and reduction of pathogenic $\mathrm{T}$-cell trafficking to target tissues and inflamed responses. Of note, the metabolic program of $\mathrm{CD} 4^{+} \mathrm{T}$ cells was found modulated in LXA4-teated mice, marked by decreased glycolytic responses associated with reduced IFN- $\gamma$ production (62). Lastly, RvE1 has been applied in a model of corneal transplantation, promoting graft survival associated with diminished Th1 and Th17 $\mathrm{CD}^{+} \mathrm{T}$ cells and inflammatory cytokines in the allogeneic transplant $(42,91)$.

In some studies, the decrease in effector $\mathrm{T}$ lymphocytes observed after SPM treatment was paralleled by an increase in Fox $3^{+}$Treg frequency and associated immunomodulatory cytokines such as IL-10 and TGF- $\beta$ (50, 51, 54, 59, 63, 85). Administration of SD-208, a TGF- $\beta$ receptor antagonist, reversed the RvD1 therapeutic effect in autoimmune neuritis, showing the closed relationship between these two modulatory pathways (50). The cross-talk between SPMs and Tregs was highlighted in a model of ischemia/reperfusion-induced acute kidney injury (IRI-AKI mice) by the abrogation of RvD1 therapeutic effect after the administration of the anti-CD25 PC61 monoclonal antibody, which preferentially depletes Tregs (51). Furthermore, the beneficial effect of RvD1 on Treg frequency was suppressed after in vivo blockade of FPR2 with a specific antagonist (Boc-1), leading to severe renal tubular injury (51).

Therefore, these experimental data support SPM-based therapy as a promising avenue for the treatment of a wide range of T-cell-mediated immune and autoimmune diseases. Especially, the in vivo therapeutic efficacy of SPMs and associated dampening of effector T-cell responses can benefit from both a direct effect on $\mathrm{T}$ cells and an indirect action through antigen- presenting cells (APCs: DCs, macrophages), expressing SPM receptors, as SPMs downregulate APC activation, expression of costimulatory molecules, and secretion of inflammatory cytokines, which subsequently prime effector T cells (72).

In terms of clinical application, a pilot study has been launched in patients undergoing total knee arthroplasty to investigate the impact of preoperative supplementation with Lipinova $^{\circledR}$ (Solutex), described as a concentrate of EPA, DHA, and SPMs (NCT03434236). However, the clinical use of SPMs as therapeutic agents is impeded by their metabolically labile and unstable state, restricted bioavailability, and rapid clearance, and thus calls for the development of SPM synthetic analogs displaying pharmacokinetic properties in compliance with in vivo usage $(92,93)$. In this line, a RvE1 mimetic, RX-10045, has been tested as an ophthalmic solution for dry eye symptoms (NCT00799552), allergic conjunctivitis (NCT01639846), and in patients undergoing cataract surgery (NCT02329743). Promising results were recently reported in a phase 1 trial evaluating the safety and efficacy of BLXA4, a LXA4 analog, to treat periodontitis (NCT02342691): daily rinsing with mouthwash containing BLXA4 reduced gingival inflammation, and this was associated with a shift in serum lipid mediators toward a pro-resolving profile (94).

The development of SPM receptor agonists is also in the pipeline, as recently documented by the study of Trilleaud et al. who tested a new anti-ChemR23 agonist antibody in models of acute and chronic colitis (induced by DSS or adoptive transfer of $\mathrm{CD}^{+} \mathrm{CD} 45 \mathrm{RB}^{\text {high }} \mathrm{T}$ cells, respectively) and inflammation-driven cancers (95). This antibody was able to activate the pro-resolving ChemR23 pathway and trigger the resolution of inflammatory responses.

\section{CONCLUSION}

SPMs display a wide range of anti-inflammatory actions, which are increasingly explored in adaptive immunity, notably through their ability to bind several GPCRs expressed by $\mathrm{T}$ cells, to regulate $\mathrm{T}$-cell functions, and to trigger the resolution of inflammatory and immune-mediated diseases in animal models. Of note, a number of studies also report SPM activity on humoral responses, with, however, some discrepant results, as RvD1 increased the production of IgM and IgG (96) while decreasing the secretion of IgE by activated B lymphocytes (97, 98). IgM and IgG production and antigen-specific memory B-cell responses were similarly reduced by LXA4 (99). Building on the potent immunoresolvent properties of SPMs and their multiple targets, these findings open a new field of investigations that may provide a better understanding of the physiological regulation of adaptive immune response and its failure in pathophysiological contexts. SPM lipidomic analyses are indeed performed in the frame of several clinical studies as a read-out of disease diagnosis and progression, inflammatory profile [for instance in COVID19 patients (100)], as well as response to therapeutic interventions (NCT04698291, NCT04452942, NCT04697719, NCT01865448, NCT04308889, NCT04377334, and NCT02719665) (101). 
In addition, the pathways governing immune regulation and resolution programs are interrelated and provide the mechanistic rationale for developing SPM-based therapeutic strategies that can be beneficial for the treatment of chronic inflammatory disorders, autoimmune diseases, and organ transplantation, notably through the control of effector T cells and boost of Tregs. This is reinforced by the positive outcomes observed in various pathological settings after dietary intervention using SPM precursors, DHA and EPA, or omega-3 lipids, which enhance SPM levels and help in controlling excessive inflammation and autoimmunity in both humans and mice (102-104). Thus, the multiple actions of SPMs on innate and adaptive immunity provide novel opportunities for SPM-based biomarker and drug development (Figure 3). The production of metabolically stable SPM analogs or receptor agonist with increased half-life, together with the design of nanocarriers to protect SPMs from degradation, may accelerate the way toward clinical translation.

\section{AUTHOR CONTRIBUTIONS}

JP-H, VC, SP, and SY wrote and revised the manuscript. All authors contributed to the article and approved the submitted version.

\section{REFERENCES}

1. Lawrence T, Gilroy DW. Chronic Inflammation: A Failure of Resolution? Int J Exp Pathol (2007) 88(2):85-94. doi: 10.1111/j.1365-2613.2006.00507.x

2. Nathan C, Ding A. Nonresolving Inflammation. Cell (2010) 140(6):871-82. doi: 10.1016/j.cell.2010.02.029

3. Nagata S, Hanayama R, Kawane K. Autoimmunity and the Clearance of Dead Cells. Cell (2010) 140(5):619-30. doi: 10.1016/j.cell.2010.02.014

4. Szondy Z, Garabuczi E, Joos G, Tsay GJ, Sarang Z. Impaired Clearance of Apoptotic Cells in Chronic Inflammatory Diseases: Therapeutic Implications. Front Immunol (2014) 5:354. doi: 10.3389/fimmu.2014.00354

5. Chiurchiù V, Leuti A, Maccarrone M. Bioactive Lipids and Chronic Inflammation: Managing the Fire Within. Front Immunol (2018) 9:38. doi: 10.3389/fimmu.2018.00038

6. Serhan CN. Pro-Resolving Lipid Mediators Are Leads for Resolution Physiology. Nature (2014) 510(7503):92-101. doi: 10.1038/nature13479

7. Serhan CN. Discovery of Specialized Pro-Resolving Mediators Marks the Dawn of Resolution Physiology and Pharmacology. Mol Aspects Med (2017) 58:1-11. doi: 10.1016/j.mam.2017.03.001

8. Chiang N, Serhan CN. Structural Elucidation and Physiologic Functions of Specialized Pro-Resolving Mediators and Their Receptors. Mol Aspects Med (2017) 58:114-29. doi: 10.1016/j.mam.2017.03.005

9. Tiberi M, Chiurchiù V. Specialized Pro-Resolving Lipid Mediators and Glial Cells: Emerging Candidates for Brain Homeostasis and Repair. Front Cell Neurosci (2021) 15:673549. doi: 10.3389/fncel.2021.673549

10. Arita M, Ohira T, Sun Y-P, Elangovan S, Chiang N, Serhan CN. Resolvin E1 Selectively Interacts With Leukotriene B4 Receptor BLT1 and ChemR23 to Regulate Inflammation. J Immunol (2007) 178(6):3912-7. doi: 10.4049/ jimmunol.178.6.3912

11. Kebir DE, Gjorstrup P, Filep JG. Resolvin E1 Promotes Phagocytosis-Induced Neutrophil Apoptosis and Accelerates Resolution of Pulmonary Inflammation. PNAS (2012) 109(37):14983-8. doi: 10.1073/pnas.1206641109

12. Buckley CD, Gilroy DW, Serhan CN. Proresolving Lipid Mediators and Mechanisms in the Resolution of Acute Inflammation. Immunity (2014) 40 (3):315-27. doi: 10.1016/j.immuni.2014.02.009

13. Serhan CN, Gupta SK, Perretti M, Godson C, Brennan E, Li Y, et al. The Atlas of Inflammation Resolution (AIR). Mol Aspects Med (2020) 74:100894. doi: 10.1016/j.mam.2020.100894

\section{FUNDING}

The laboratory of SY and JP-H is supported by grants from the EFSD/JDRF/Lilly European Programme in Type 1 Diabetes Research 2019, the Agence Nationale de la Recherche (ANR-17CE17-0004, ANR-18-IDEX-0001), the Fondation pour la Recherche Médicale (EQU20193007831), the Association des Jeunes Diabétiques, and the Innovative Medicines Initiative 2 Joint Undertaking under grant agreements 115797 and 945268 (INNODIA and INNODIA HARVEST), which receive support from the EU Horizon 2020 program, the European Federation of Pharmaceutical Industries and Associations, JDRF, and The Leona M. and Harry B. Helmsley Charitable Trust. VC is funded by the Italian Ministry of Health (grant GR-201602362380), the Italian Foundation of Multiple Sclerosis (FISM 2017/R/08), and the MAI Award Grant (MAI-VC-2021). SP is funded by the Conseil Régional de Franche-Comté (AAP 2019), the Agence Nationale de la Recherche (ANR-11-LABX-0021 and ANR-17-CE17-0004), BPI France (grant No. DOS0060162/00), and the European Union through the European Regional Development Fund of the Région Bourgogne-FrancheComte (FC0013440).

14. Serhan CN, Levy BD. Resolvins in Inflammation: Emergence of the ProResolving Superfamily of Mediators. J Clin Invest (2018) 128(7):2657-69. doi: 10.1172/JCI97943

15. Leuti A, Fazio D, Fava M, Piccoli A, Oddi S, Maccarrone M. Bioactive Lipids, Inflammation and Chronic Diseases. Advanced Drug Deliv Rev (2020) 159:133-69. doi: 10.1016/j.addr.2020.06.028

16. Goodarzi K, Goodarzi M, Tager AM, Luster AD, von Andrian UH Leukotriene B4 and BLT1 Control Cytotoxic Effector T Cell Recruitment to Inflamed Tissues. Nat Immunol (2003) 4(10):965-73. doi: 10.1038/ni972

17. Islam SA, Thomas SY, Hess C, Medoff BD, Means TK, Brander C, et al. The Leukotriene B4 Lipid Chemoattractant Receptor BLT1 Defines AntigenPrimed T Cells in Humans. Blood (2006) 107(2):444-53. doi: 10.1182/blood2005-06-2362

18. Tager AM, Bromley SK, Medoff BD, Islam SA, Bercury SD, Friedrich EB et al. Leukotriene B4 Receptor BLT1 Mediates Early Effector T Cell Recruitment. Nat Immunol (2003) 4(10):982-90. doi: 10.1038/ni970

19. Medoff BD, Seung E, Wain JC, Means TK, Campanella GSV, Islam SA, et al. BLT1-Mediated T Cell Trafficking is Critical for Rejection and Obliterative Bronchiolitis After Lung Transplantation. J Exp Med (2005) 202(1):97-110 doi: $10.1084 /$ jem.20042481

20. Miyahara N, Takeda K, Miyahara S, Taube C, Joetham A, Koya T, et al. Leukotriene B4 Receptor-1 Is Essential for Allergen-Mediated Recruitment of CD8 ${ }^{+}$T Cells and Airway Hyperresponsiveness. J Immunol (2005) 174 (8):4979-84. doi: 10.4049/jimmunol.174.8.4979

21. Taube C, Miyahara N, Ott V, Swanson B, Takeda K, Loader J, et al. The Leukotriene B4 Receptor (BLT1) Is Required for Effector CD8 ${ }^{+} \mathrm{T}$ CellMediated, Mast Cell-Dependent Airway Hyperresponsiveness. J Immunol (2006) 176(5):3157-64. doi: 10.4049/jimmunol.176.5.3157

22. Lv J, Zou L, Zhao L, Yang W, Xiong Y, Li B, et al. Leukotriene $B_{4}$-Leukotriene $\mathrm{B}_{4}$ Receptor Axis Promotes Oxazolone-Induced Contact Dermatitis by Directing Skin Homing of Neutrophils and $\mathrm{CD}^{+} \mathrm{T}$ Cells. Immunol (2015) 146(1):50-8. doi: 10.1111/imm.12478

23. Sharma RK, Chheda Z, Jala VR, Haribabu B. Expression of Leukotriene B4 Receptor-1 on CD8+ T Cells Is Required for Their Migration Into Tumors To Elicit Effective Antitumor Immunity. J Immunol (2013) 191(6):3462-70. doi: 10.4049/jimmunol.1300967

24. Chen H, Qin J, Wei P, Zhang J, Li Q, Fu L, et al. Effects of Leukotriene B4 and Prostaglandin E2 on the Differentiation of Murine Foxp3+ T Regulatory 
Cells and Th17 Cells. Prostaglandins Leukot Essent Fatty Acids (2009) 80 (4):195-200. doi: 10.1016/j.plefa.2009.01.006

25. Lee W, Su Kim H, Lee GR. Leukotrienes Induce the Migration of Th17 Cells. Immunol Cell Biol (2015) 93(5):472-9. doi: 10.1038/icb.2014.104

26. Nagaya T, Kawata K, Kamekura R, Jitsukawa S, Kubo T, Kamei M, et al. Lipid Mediators Foster the Differentiation of T Follicular Helper Cells. Immunol Lett (2017) 181:51-7. doi: 10.1016/j.imlet.2016.11.006

27. Maseda D, Ricciotti E, Crofford LJ. Prostaglandin Regulation of T Cell Biology. Pharmacol Res (2019) 149:104456. doi: 10.1016/j.phrs.2019.104456

28. Yao C, Hirata T, Soontrapa K, Ma X, Takemori H, Narumiya S. Prostaglandin $\mathrm{E}_{2}$ Promotes Th1 Differentiation via Synergistic Amplification of IL-12 Signalling by cAMP and PI3-Kinase. Nat Commun (2013) 4:1685. doi: 10.1038/ncomms2684

29. Chen Q, Muramoto K, Masaaki N, Ding Y, Yang H, Mackey M, et al. A Novel Antagonist of the Prostaglandin E(2) EP(4) Receptor Inhibits Th1 Differentiation and Th17 Expansion and is Orally Active in Arthritis Models. Br J Pharmacol (2010) 160(2):292-310. doi: 10.1111/j.14765381.2010.00647.x

30. Lee J, Aoki T, Thumkeo D, Siriwach R, Yao C, Narumiya S. T Cell-Intrinsic Prostaglandin E2-EP2/EP4 Signaling Is Critical in Pathogenic TH17 CellDriven Inflammation. J Allergy Clin Immunol (2019) 143(2):631-43. doi: 10.1016/j.jaci.2018.05.036

31. Esaki Y, Li Y, Sakata D, Yao C, Segi-Nishida E, Matsuoka T, et al. Dual Roles of PGE2-EP4 Signaling in Mouse Experimental Autoimmune Encephalomyelitis. Proc Natl Acad Sci USA (2010) 107(27):12233-8. doi: 10.1073/pnas.0915112107

32. Hooper KM, Kong W, Ganea D. Prostaglandin E2 Inhibits Tr1 Cell Differentiation Through Suppression of C-Maf. PloS One (2017) 12(6): e0179184. Kim CH, editor. doi: 10.1371/journal.pone.0179184

33. Li H, Chen H-Y, Liu W-X, Jia X-X, Zhang J-G, Ma C-L, et al. Prostaglandin E2 Restrains Human Treg Cell Differentiation via E Prostanoid Receptor 2Protein Kinase A Signaling. Immunol Lett (2017) 191:63-72. doi: 10.1016/ j.imlet.2017.09.009

34. Baratelli F, Lin Y, Zhu L, Yang S-C, Heuzé-Vourc'h N, Zeng G, et al. Prostaglandin E2 Induces FOXP3 Gene Expression and T Regulatory Cell Function in Human CD4+ T Cells. J Immunol (2005) 175(3):1483-90. doi: 10.4049/jimmunol.175.3.1483

35. Ariel A, Chiang N, Arita M, Petasis NA, Serhan CN. Aspirin-Triggered Lipoxin $\mathrm{A}_{4}$ and $\mathrm{B}_{4}$ Analogs Block Extracellular Signal-Regulated KinaseDependent TNF- $\alpha$ Secretion From Human T Cells. J Immunol (2003) 170 (12):6266-72. doi: 10.4049/jimmunol.170.12.6266

36. Spurr L, Nadkarni S, Pederzoli-Ribeil M, Goulding NJ, Perretti M, D'Acquisto F. Comparative Analysis of Annexin A1-Formyl Peptide Receptor 2/ALX Expression in Human Leukocyte Subsets. Int Immunopharmacol (2011) 11(1):55-66. doi: 10.1016/j.intimp.2010.10.006

37. Gao Y, Min K, Zhang Y, Su J, Greenwood M, Gronert K. Female-Specific Downregulation of Tissue Polymorphonuclear Neutrophils Drives Impaired Regulatory T Cell and Amplified Effector T Cell Responses in Autoimmune Dry Eye Disease. J Immunol (2015) 195(7):3086-99. doi: 10.4049/jimmunol.1500610

38. Derada Troletti C, Enzmann G, Chiurchiù V, Kamermans A, Tietz SM, Norris PC, et al. Pro-Resolving Lipid Mediator Lipoxin A4 Attenuates Neuro-Inflammation by Modulating T Cell Responses and Modifies the Spinal Cord Lipidome. Cell Rep (2021) 35(9):109201. doi: 10.1016/ j.celrep.2021.109201

39. Haworth O, Cernadas M, Yang R, Serhan CN, Levy BD. Resolvin E1 Regulates Interleukin 23, Interferon- $\gamma$ and Lipoxin A4 to Promote the Resolution of Allergic Airway Inflammation. Nat Immunol (2008) 9 (8):873-9. doi: 10.1038/ni.1627

40. Rajasagi NK, Reddy PBJ, Suryawanshi A, Mulik S, Gjorstrup P, Rouse BT. Controlling Herpes Simplex Virus-Induced Ocular Inflammatory Lesions With the Lipid-Derived Mediator Resolvin E1. J. Immunol (2011) 186 (3):1735-46. doi: 10.4049/jimmunol.1003456

41. Sawada Y, Honda T, Nakamizo S, Otsuka A, Ogawa N, Kobayashi Y, et al. Resolvin E1 Attenuates Murine Psoriatic Dermatitis. Sci Rep (2018) 8 (1):11873. doi: 10.1038/s41598-018-30373-1

42. Wang H, Zhao Q, Luo D, Yin Y, Li T, Zhao M. Resolvin E1 Inhibits Corneal Allograft Rejection in High-Risk Corneal Transplantation. Invest Ophthalmol Vis Sci (2018) 59(10):3911. doi: 10.1167/iovs.18-24562
43. Alvarez C, Abdalla H, Sulliman S, Rojas P, Wu Y-C, Almarhoumi R, et al. RvE1 Impacts the Gingival Inflammatory Infiltrate by Inhibiting the T Cell Response in Experimental Periodontitis. Front Immunol (2021) 12:664756. doi: 10.3389/fimmu.2021.664756

44. Sawada Y, Honda T, Hanakawa S, Nakamizo S, Murata T, UeharaguchiTanada Y, et al. Resolvin E1 Inhibits Dendritic Cell Migration in the Skin and Attenuates Contact Hypersensitivity Responses. J Exp Med (2015) 212 (11):1921-30. doi: 10.1084/jem.20150381

45. Liu G, Gong Y, Zhang R, Piao L, Li X, Liu Q, et al. Resolvin E1 Attenuates Injury-Induced Vascular Neointimal Formation by Inhibition of Inflammatory Responses and Vascular Smooth Muscle Cell Migration. FASEB J (2018) 32(10):5413-25. doi: 10.1096/fj.201800173R

46. Settimio R, Clara DF, Franca F, Francesca S, Michele D. Resolvin D1 Reduces the Immunoinflammatory Response of the Rat Eye Following Uveitis. Mediators Inflamm (2012) 2012:1-9. doi: 10.1155/2012/318621

47. Rossi S, Di Filippo C, Gesualdo C, Potenza N, Russo A, Trotta MC, et al. Protection From Endotoxic Uveitis by Intravitreal Resolvin D1: Involvement of Lymphocytes, miRNAs, Ubiquitin-Proteasome, and M1/M2 Macrophages. Mediators Inflamm (2015) 2015:1-12. doi: 10.1155/2015/ 149381

48. Poisson LM, Suhail H, Singh J, Datta I, Denic A, Labuzek K, et al. Untargeted Plasma Metabolomics Identifies Endogenous Metabolite With Drug-Like Properties in Chronic Animal Model of Multiple Sclerosis. J Biol Chem (2015) 290(52):30697-712. doi: 10.1074/jbc.M115.679068

49. Saban DR, Hodges RR, Mathew R, Reyes NJ, Yu C, Kaye R, et al. Resolvin D1 Treatment on Goblet Cell Mucin and Immune Responses in the Chronic Allergic Eye Disease (AED) Model. Mucosal Immunol (2019) 12(1):145-53. doi: 10.1038/s41385-018-0089-1

50. Luo B, Han F, Xu K, Wang J, Liu Z, Shen Z, et al. Resolvin D1 Programs Inflammation Resolution by Increasing TGF- Expression Induced by Dying Cell Clearance in Experimental Autoimmune Neuritis. J Neurosci (2016) 36 (37):9590-603. doi: 10.1523/JNEUROSCI.0020-16.2016

51. Luan H, Wang C, Sun J, Zhao L, Li L, Zhou B, et al. Resolvin D1 Protects Against Ischemia/Reperfusion-Induced Acute Kidney Injury by Increasing Treg Percentages via the ALX/FPR2 Pathway. Front Physiol (2020) 11:285. doi: 10.3389/fphys.2020.00285

52. Chiurchiù V, Leuti A, Dalli J, Jacobsson A, Battistini L, Maccarrone M, et al. Proresolving Lipid Mediators Resolvin D1, Resolvin D2, and Maresin 1 are Critical in Modulating T Cell Responses. Sci Transl Med (2016) 8 (353):353ra111. doi: 10.1126/scitranslmed.aaf7483

53. Kuang H, Hua X, Zhou J, Yang R. Resolvin D1 and E1 Alleviate the Progress of Hepatitis Toward Liver Cancer in Long-Term Concanavalin A-Induced Mice Through Inhibition of NF-kb Activity. Oncol Rep (2016) 35(1):307-17. doi: 10.3892/or.2015.4389

54. Mizraji G, Heyman O, Van Dyke TE, Wilensky A. Resolvin D2 Restrains Th1 Immunity and Prevents Alveolar Bone Loss in Murine Periodontitis. Front Immunol (2018) 9:785. doi: 10.3389/fimmu.2018.00785

55. Ariel A, Li P-L, Wang W, Tang W-X, Fredman G, Hong S, et al. The Docosatriene Protectin D1 Is Produced by TH2 Skewing and Promotes Human T Cell Apoptosis via Lipid Raft Clustering. J Biol Chem (2005) 280 (52):43079-86. doi: 10.1074/jbc.M509796200

56. Park KD, Kim N, Kang J, Dhakal H, Kim JY, Jang YH, et al. Protectin D1 Reduces Imiquimod-Induced Psoriasiform Skin Inflammation. Int Immunopharmacol (2021) 98:107883. doi: 10.1016/j.intimp.2021.107883

57. Rajasagi NK, Reddy PBJ, Mulik S, Gjorstrup P, Rouse BT. Neuroprotectin D1 Reduces the Severity of Herpes Simplex Virus-Induced Corneal Immunopathology. Invest Ophthalmol Vis Sci (2013) 54(9):6269-79. doi: 10.1167/iovs.13-12152

58. Krishnamoorthy N, Burkett PR, Dalli J, Abdulnour R-EE, Colas R, Ramon S, et al. Cutting Edge: Maresin-1 Engages Regulatory T Cells To Limit Type 2 Innate Lymphoid Cell Activation and Promote Resolution of Lung Inflammation. JI (2015) 194(3):863-7. doi: 10.4049/ jimmunol.1402534

59. Jin S, Chen H, Li Y, Zhong H, Sun W, Wang J, et al. Maresin 1 Improves the Treg/Th17 Imbalance in Rheumatoid Arthritis Through miR-21. Ann Rheum Dis (2018) 77(11):1644-52. doi: 10.1136/annrheumdis-2018-213511

60. Saito-Sasaki N, Sawada Y, Mashima E, Yamaguchi T, Ohmori S, Yoshioka H, et al. Maresin-1 Suppresses Imiquimod-Induced Skin Inflammation by 
Regulating IL-23 Receptor Expression. Sci Rep (2018) 8(1):5522. doi: 10.1038/s41598-018-23623-9

61. Wang H, Shi P, Huang C, Liu Q. Maresin 1 Ameliorates Iron-Deficient Anemia in IL-10-/- Mice With Spontaneous Colitis by the Inhibition of Hepcidin Expression Though the IL-6/STAT3 Pathway. Am J Transl Res (2016) 8(6):2758-66.

62. Wei J, Mattapallil MJ, Horai R, Jittayasothorn Y, Modi AP, Sen HN, et al. A Novel Role for Lipoxin A4 in Driving a Lymph Node-Eye Axis That Controls Autoimmunity to the Neuroretina. eLife (2020) 9:e51102. doi: 10.7554/eLife.51102

63. Cheng T, Ding S, Liu S, Li X, Tang X, Sun L. Resolvin D1 Improves the Treg/ Th17 Imbalance in Systemic Lupus Erythematosus Through miR-30e-5p. Front Immunol (2021) 12:668760. doi: 10.3389/fimmu.2021.668760

64. Levy BD, Kohli P, Gotlinger K, Haworth O, Hong S, Kazani S, et al. Protectin D1 is Generated in Asthma and Dampens Airway Inflammation and Hyperresponsiveness. J Immunol (2007) 178(1):496-502. doi: 10.4049/ jimmunol.178.1.496

65. Rogerio AP, Haworth O, Croze R, Oh SF, Uddin M, Carlo T, et al. Resolvin D1 and Aspirin-Triggered Resolvin D1 Promote Resolution of Allergic Airways Responses. J Immunol (2012) 189(4):1983-91. doi: 10.4049/ jimmunol.1101665

66. Aoki H, Hisada T, Ishizuka T, Utsugi M, Kawata T, Shimizu Y, et al. Resolvin E1 Dampens Airway Inflammation and Hyperresponsiveness in a Murine Model of Asthma. Biochem Biophys Res Commun (2008) 367(2):509-15. doi: 10.1016/j.bbrc.2008.01.012

67. Aoki H, Hisada T, Ishizuka T, Utsugi M, Ono A, Koga Y, et al. Protective Effect of Resolvin E1 on the Development of Asthmatic Airway Inflammation. Biochem Biophys Res Commun (2010) 400(1):128-33. doi: 10.1016/j.bbrc.2010.08.025

68. Kim T-H, Kim G-D, Jin Y-H, Park YS, Park C-S. Omega-3 Fatty AcidDerived Mediator, Resolvin E1, Ameliorates 2,4-DinitrofluorobenzeneInduced Atopic Dermatitis in NC/Nga Mice. Int Immunopharmacol (2012) 14(4):384-91. doi: 10.1016/j.intimp.2012.08.005

69. Vassiliou EK, Kesler OM, Tadros JH, Ganea D. Bone Marrow-Derived Dendritic Cells Generated in the Presence of Resolvin E1 Induce Apoptosis of Activated CD4+ T Cells. J Immunol (2008) 181(7):4534-44. doi: 10.4049/ jimmunol.181.7.4534

70. Tian H, Lu Y, Sherwood AM, Hongqian D, Hong S. Resolvins E1 and D1 in Choroid-Retinal Endothelial Cells and Leukocytes: Biosynthesis and Mechanisms of Anti-Inflammatory Actions. Invest Ophthalmol Vis Sci (2009) 50(8):3613-20. doi: 10.1167/iovs.08-3146

71. Li N, He J, Schwartz CE, Gjorstrup P, Bazan HEP. Resolvin E1 Improves Tear Production and Decreases Inflammation in a Dry Eye Mouse Model. J Ocul Pharmacol Ther (2010) 26(5):431-9. doi: 10.1089/jop.2010.0019

72. Oner F, Alvarez C, Yaghmoor W, Stephens D, Hasturk H, Firatli E, et al. Resolvin E1 Regulates Th17 Function and T Cell Activation. Front Immunol (2021) 12:637983. doi: 10.3389/fimmu.2021.637983

73. Bang S, Xie Y-K, Zhang Z-J, Wang Z, Xu Z-Z, Ji R-R. GPR37 Regulates Macrophage Phagocytosis and Resolution of Inflammatory Pain. J Clin Invest (2018) 128(8):3568-82. doi: 10.1172/JCI99888

74. Chiang N, Libreros S, Norris PC, de la Rosa X, Serhan CN. Maresin 1 Activates LGR6 Receptor Promoting Phagocyte Immunoresolvent Functions. J Clin Invest (2019) 129(12):5294-311. doi: 10.1172/JCI129448

75. Smigiel KS, Srivastava S, Stolley JM, Campbell DJ. Regulatory T-Cell Homeostasis: Steady-State Maintenance and Modulation During Inflammation. Immunol Rev (2014) 259(1):40-59. doi: 10.1111/imr.12170

76. Proto JD, Doran AC, Gusarova G, Yurdagul A, Sozen E, Subramanian M, et al. Regulatory $\mathrm{T}$ Cells Promote Macrophage Efferocytosis During Inflammation Resolution. Immunity (2018) 49(4):666-677.e6. doi: 10.1016/j.immuni.2018.07.015

77. Sharma M, Schlegel MP, Afonso MS, Brown EJ, Rahman K, Weinstock A, et al. Regulatory T Cells License Macrophage Pro-Resolving Functions During Atherosclerosis Regression. Circ Res (2020) 127(3):335-53. doi: 10.1161/CIRCRESAHA.119.316461

78. Gagliani N, Amezcua Vesely MC, Iseppon A, Brockmann L, Xu H, Palm NW, et al. Th17 Cells Transdifferentiate Into Regulatory T Cells During Resolution of Inflammation. Nature (2015) 523(7559):221-5. doi: 10.1038/ nature 14452
79. Gao Y, Su J, Zhang Y, Chan A, Sin JH, Wu D, et al. Dietary DHA Amplifies LXA4 Circuits in Tissues and Lymph Node PMN and is Protective in Immune-Driven Dry Eye Disease. Mucosal Immunol (2018) 11(6):1674-83. doi: 10.1038/s41385-018-0070-z

80. Ariyoshi T, Hagihara M, Eguchi S, Fukuda A, Iwasaki K, Oka K, et al. Clostridium Butyricum MIYAIRI 588-Induced Protectin D1 Has an AntiInflammatory Effect on Antibiotic-Induced Intestinal Disorder. Front Microbiol (2020) 11:587725. doi: 10.3389/fmicb.2020.587725

81. Marques RM, Gonzalez-Nunez M, Walker ME, Gomez EA, Colas RA, Montero-Melendez T, et al. Loss of 15-Lipoxygenase Disrupts Treg Differentiation Altering Their Pro-Resolving Functions. Cell Death Differ (2021) 28(11):3140-60. doi: 10.1038/s41418-021-00807-x

82. Chung EH, Jia Y, Ohnishi H, Takeda K, Leung DYM ， Sutherland ER, et al. Leukotriene B4 Receptor 1 is Differentially Expressed on Peripheral T Cells of Steroid-Sensitive and -Resistant Asthmatics. Ann Allergy Asthma Immunol (2014) 112(3):211-6.el. doi: 10.1016/j.anai.2013.12.006

83. Chiurchiù V, Leuti A, Saracini S, Fontana D, Finamore P, Giua R, et al. Resolution of Inflammation is Altered in Chronic Heart Failure and Entails a Dysfunctional Responsiveness of T Lymphocytes. FASEB J (2019) 33 (1):909-16. doi: 10.1096/fj.201801017R

84. Kooij G, Troletti CD, Leuti A, Norris PC, Riley I, Albanese M, et al. Specialized Pro-Resolving Lipid Mediators are Differentially Altered in Peripheral Blood of Patients With Multiple Sclerosis and Attenuate Monocyte and Blood-Brain Barrier Dysfunction. Haematologica (2020) 105(8):2056-70. doi: 10.3324/haematol.2019.219519

85. Jin S, Sun S, Ling H, Ma J, Zhang X, Xie Z, et al. Protectin DX Restores Treg/ Th17 Cell Balance in Rheumatoid Arthritis by Inhibiting NLRP3 Inflammasome via miR-20a. Cell Death Dis (2021) 12(3):280. doi: $10.1038 / s 41419-021-03562-6$

86. Arnardottir HH, Dalli J, Norling LV, Colas RA, Perretti M, Serhan CN. Resolvin D3 Is Dysregulated in Arthritis and Reduces Arthritic Inflammation. J Immunol (2016) 197(6):2362-8. doi: 10.4049/jimmunol. 1502268

87. Silva CAM, Webb K, Andre BG, Marques MA de M, de Carvalho FM, de Macedo CS, et al. Type 1 Reaction in Leprosy Patients Corresponds With a Decrease in Pro-Resolving and an Increase in Pro-Inflammatory Lipid Mediators. J Infect Dis (2016) 215(3):431-9. doi: 10.1093/infdis/jiw541

88. Xia H, Wang F, Wang M, Wang J, Sun S, Chen M, et al. Maresin1 Ameliorates Acute Lung Injury Induced by Sepsis Through Regulating Th17/Treg Balance. Life Sci (2020) 254:117773. doi: 10.1016/j.lfs.2020.117773

89. Rajasagi NK, Bhela S, Varanasi SK, Rouse BT. Frontline Science: AspirinTriggered Resolvin D1 Controls Herpes Simplex Virus-Induced Corneal Immunopathology. J Leukoc Biol (2017) 102(5):1159-71. doi: 10.1189/ jlb.3HI1216-511RR

90. Dean S, Wang C-S, Nam K, Maruyama CL, Trump BG, Baker OJ. Aspirin Triggered Resolvin D1 Reduces Inflammation and Restores Saliva Secretion in a Sjögren's Syndrome Mouse Model. Rheumatol (2019) 58(7):1285-92. doi: 10.1093/rheumatology/kez072

91. Hua J, Jin Y, Chen Y, Inomata T, Lee H, Chauhan SK, et al. The Resolvin D1 Analogue Controls Maturation of Dendritic Cells and Suppresses Alloimmunity in Corneal Transplantation. Invest Ophthalmol Vis Sci (2014) 55(9):5944. doi: 10.1167/iovs.14-14356

92. Arita M, Oh SF, Chonan T, Hong S, Elangovan S, Sun Y-P, et al. Metabolic Inactivation of Resolvin E1 and Stabilization of its Anti-Inflammatory Actions. J Biol Chem (2006) 281(32):22847-54. doi: 10.1074/ jbc.M603766200

93. Orr SK, Colas RA, Dalli J, Chiang N, Serhan CN. Proresolving Actions of a New Resolvin D1 Analog Mimetic Qualifies as an Immunoresolvent. Am J Physiol Lung Cell Mol Physiol (2015) 308(9):L904-911. doi: 10.1152/ ajplung.00370.2014

94. Hasturk H, Schulte F, Martins M, Sherzai H, Floros C, Cugini M, et al. Safety and Preliminary Efficacy of a Novel Host-Modulatory Therapy for Reducing Gingival Inflammation. Front Immunol (2021) 12:704163. doi: 10.3389/ fimmu.2021.704163

95. Trilleaud C, Gauttier V, Biteau K, Girault I, Belarif L, Mary C, et al. Agonist Anti-ChemR23 mAb Reduces Tissue Neutrophil Accumulation and Triggers Chronic Inflammation Resolution. Sci Adv (2021) 7(14):eabd1453. doi: $10.1126 /$ sciadv.abd1453 
96. Ramon S, Gao F, Serhan CN, Phipps RP. Specialized Proresolving Mediators Enhance Human B Cell Differentiation to Antibody-Secreting Cells. J Immunol (2012) 189(2):1036-42. doi: 10.4049/jimmunol.1103483

97. Kim N, Ramon S, Thatcher TH, Woeller CF, Sime PJ, Phipps RP. Specialized Proresolving Mediators (SPMs) Inhibit Human B-Cell IgE Production. Eur J Immunol (2016) 46(1):81-91. doi: 10.1002/eji.201545673

98. Kim N, Thatcher TH, Sime PJ, Phipps RP. Corticosteroids Inhibit AntiIgE Activities of Specialized Proresolving Mediators on B Cells From Asthma Patients. JCI Insight (2017) 2(3):e88588. doi: 10.1172/jci.insight. 88588

99. Ramon S, Bancos S, Serhan CN, Phipps RP. Lipoxin $\mathrm{A}_{4}$ Modulates Adaptive Immunity by Decreasing Memory B-Cell Responses via an ALX/FPR2Dependent Mechanism. Eur J Immunol (2014) 44(2):357-69. doi: 10.1002/ eji.201343316

100. Archambault A-S, Zaid Y, Rakotoarivelo V, Turcotte C, Doré É, Dubuc I, et al. High Levels of Eicosanoids and Docosanoids in the Lungs of Intubated COVID-19 Patients. FASEB J (2021) 35(6):e21666. doi: 10.1096/ fj.202100540R

101. Schaller MS, Chen M, Colas RA, Sorrentino TA, Lazar AA, Grenon SM, et al. Treatment With a Marine Oil Supplement Alters Lipid Mediators and Leukocyte Phenotype in Healthy Patients and Those With Peripheral Artery Disease. J Am Heart Assoc (2020) 9(15):e016113. doi: 10.1161/ JAHA.120.016113

102. Li X, Bi X, Wang S, Zhang Z, Li F, Zhao AZ. Therapeutic Potential of $\omega-3$ Polyunsaturated Fatty Acids in Human Autoimmune Diseases. Front Immunol (2019) 10:2241. doi: 10.3389/fimmu.2019.02241
103. Barry AR, Dixon DL. Omega-3 Fatty Acids for the Prevention of Atherosclerotic Cardiovascular Disease. Pharmacotherapy (2021). doi: 10.1002/phar.2615

104. Djuricic I, Calder PC. Beneficial Outcomes of Omega- 6 and Omega-3 Polyunsaturated Fatty Acids on Human Health: An Update for 2021. Nutrients (2021) 13(7):2421. doi: 10.3390/nu13072421

Conflict of Interest: SP is the CEO and shareholder of MED'INN'Pharma, which develops pro-resolutive drug candidates.

The remaining authors declare that the research was conducted in the absence of any commercial or financial relationships that could be construed as a potential conflict of interest.

Publisher's Note: All claims expressed in this article are solely those of the authors and do not necessarily represent those of their affiliated organizations, or those of the publisher, the editors and the reviewers. Any product that may be evaluated in this article, or claim that may be made by its manufacturer, is not guaranteed or endorsed by the publisher.

Copyright (C) 2021 Perez-Hernandez, Chiurchiù, Perruche and You. This is an openaccess article distributed under the terms of the Creative Commons Attribution License (CC BY). The use, distribution or reproduction in other forums is permitted, provided the original author(s) and the copyright owner(s) are credited and that the original publication in this journal is cited, in accordance with accepted academic practice. No use, distribution or reproduction is permitted which does not comply with these terms. 